\title{
Wireless power transfer system design for electric vehicle dynamic charging application
}

\author{
Nguyen Thi Diep ${ }^{1}$, Nguyen Kien Trung ${ }^{2}$, Tran Trong Minh ${ }^{3}$ \\ 1,2,3 Department of Industrial Automation, Hanoi University of Science and Technology, Vietnam \\ ${ }^{1}$ Department of Automation and Control Engineering Technology, Electric Power University, Vietnam
}

\begin{tabular}{l}
\hline Article Info \\
\hline Article history: \\
Received Dec 12, 2019 \\
Revised Feb 4, 2020 \\
Accepted May 6, 2020 \\
\hline
\end{tabular}

\section{Keywords:}

Dynamic wireless charging Electric vehicle LCC compensation circuit Wireless power transfer

\begin{abstract}
This paper proposes and demonstrates a wireless power transfer system design for electric vehicle dynamic charging applications. The dynamic wireless charging (DWC) lane is designed for modularly. Each module has three shorttrack transmitter coils that are placed closely together and connected to a single inverter to reduce the number of inverters. The magnetic coupler design is analyzed and optimized by finite element analysis (FEA) to reduce the output power variation during dynamic charging. The LCC compensation circuit is designed according to the optimal load value to obtain maximum efficiency. The SIC devices are used to improve the efficiency of the high-frequency resonant inverter. A $1.5 \mathrm{~kW}$ dynamic charging system prototype is constructed. Experimental results show that the output power variation of $9.5 \%$ and the average efficiency of $89.5 \%$ are obtained in the moving condition.
\end{abstract}

This is an open access article under the CC BY-SA license.

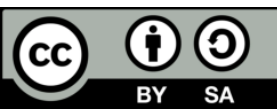

\section{Corresponding Author:}

Nguyen Kien Trung,

Department of Industrial Automation,

Hanoi University of Science and Technology,

No. 1 Dai Co Viet Road, Hai Ba Trung, Hanoi, Viet Nam.

Email: trung.nguyenkien1@ hust.edu.vn

\section{INTRODUCTION}

Today, problem of environmental pollution is increasing seriously, and fossil resources are exhausting. Using electric vehicles (EV) helps reduce greenhouse gas emissions. The current charger for EV is mainly plugged-in, usually located at home, at work, or centralized charging stations. However, plugged-in chargers make inconvenience, easy to electric leakage. Wireless charging is based on wireless power transfer (WPT) technology, which makes using EVs more convenient and safer [1]. Wireless charging has two categories, that is static wireless charging (SWC) and dynamic wireless charging. In the SWC system, when charging, electric vehicles must be parked in alignment with the transmitter to receive power from the transmitter. However, the capacity and energy density of batteries limit the development of the SWC [2]. In the DWC system, EVs can charge while it is moving. Therefore, EVs can move longer, battery capacity and weight may be smaller, and transportation efficiency improves [3]. Therefore, DWC system research and development can promote the development of EV in the future. However, the movement of EV creates many challenges for the design and control system [4].

The design of the magnetic coupler is considered one of the most important factors in the DWC system [5]. In the DWC system, the magnetic components are composed of a transmitter lane, which is usually under the road and a receiver coils, which is mounted under an EV. The transmitter lanes in the DWC systems can be classified into two main types, either long-track transmitters or short-track transmitters. The long-track transmitter structures have high inductance, low coupling coefficients, and low resonant frequency [6]. 
Therefore, these transmitter lanes have low efficiency and high electromagnetic interference (EMI) [7]. Shorttrack transmitters used to reduce EMI and increase efficiency [8]. Each short-track transmitter can be the same size as a pad in the SWC. The transmitter lane is formed by arranging multiple short-track transmitters together. Each transmitter coil has a separate compensation circuit, so it is very flexible to design and expand the transmitter line. Besides, each short-track transmitter can be switched ON/OFF according to the EV position. Therefore, the efficiency and EMI of this transmitter lane are higher [9]. However, this system is complexity, as it requires a large number of compensation circuits, power converters, EV position detection circuits [10]. Furthermore, the coupling coefficient is variation when EV is moving along the transmitter lane. Therefore, the output power is pulsation and significantly reduced when the EVs move misalignment direction, which affects battery life [11]. Several studies on the solution to reduce the output pulsation have been realized. In [12], the distance between adjacent transmitters adjusted to reduce the power pulsation. This reduces the overall length of the transmitter lane. In [13], the receiver length has optimized for a three-phase dynamic IPT system with dual pick-up coil that has used to reduce the variation of output power. In [14] proposed solutions to reduce the pulsation of output power by placing the transmitter coils close to each other and coils size is optimized by FEA simulation. These papers perform optimizing the size of the transmitters and receivers to reduce pulsation power. However, the survey results are only performed in case EV moves in a straight direction. The characteristics of coupling coefficients according to positions when EVs moves in the misalignment direction have not been reported. It is an important feature for the design and control of a DWC system. Furthermore, the design of compensation circuits does not consider the impedance matching problem then the maximum efficiency is difficult to obtain.

In this paper, the magnetic coupler design is also optimized by FEA simulation to reduce the coupling coefficients variation during the dynamic charging process. And then, when EV moves misalignment, the characteristics of the coupling coefficients are analyzed to provide a basis for advanced controls, such as output power control in [15], impedance control in [16]. The compensation circuit is designed based on the impedance matching condition to obtain maximum transfer efficiency.

In the DWC systems, energy transfers through the air, so large leakage inductance. Therefore, reactive power is high, and transfer efficiency is low. Compensation circuits are necessary to adjust the system resonant frequency, reduce the reactive power of the power electronics converter, improve transfer efficiency. At the frequency of $\mathrm{kHz}$, capacitors are connected to the coil to compensate for the leakage inductance. There are four basic compensation circuits, which are series-series (SS), series-parallel (SP), parallel-series (PS) and parallel-parallel (PP) $[17,18]$. These compensation circuits are simple and easy to design. However, the limitation is sensitive to the parameter variation [19]. Transfer power and efficiency characteristics are separated when the load changes [20,21]. The SP, PS, PP compensation circuits have resonant frequency depending on the coupling coefficient [22]. Therefore, these compensation circuits are not suitable for dynamic charging systems, in which the coupling coefficient changes according to the EVs position. The LCC compensation circuit has proposed in [23] overcomes these disadvantages. The resonant frequency is independent of the coupling coefficient as well as the load impedance and the soft-switching condition for the MOSFET reaches. These feature of the LCC compensation circuit is similar to the SS compensation circuit. However, with the same design power, the size of elements in the LCC compensation circuit is smaller than the SS compensation circuit. It has practical significance when designing high power systems. In [14], LCC compensation circuits have designed for dynamic wireless charging, which primary compensation inductances have designed to be two times larger than the secondary compensation inductance. As a result, transfer efficiency does not reach the maximum value at the design point. This paper proposed a method for calculating compensation circuit parameters according to the optimum load value to maximize transfer efficiency. Therefore, if the load impedance is always kept equal to the optimum load value as in [16], the transfer efficiency reaches the maximum value over a wide frequency range. Furthermore, the frequency can be controlled around $85 \mathrm{kHz}$ to improve inverter efficiency, such as zero phase angle tracking control as in [24].

A dynamic charging system prototype with a power of $1.5 \mathrm{~kW}$ is constructed. The average value of efficiency during dynamic charging is $89.5 \%$. The variation of the output power is $9.5 \%$. Section 2 gives the system structure and magnetic coupler design. Section 3 presents the method of the LCC compensation circuit design to maximum efficiency. Section 4 presents simulation and experimental results. Finally, the conclusions are given in Section 5.

\section{SYSTEM STRUCTURE AND MAGNETIC COUPLER DESIGN}

\subsection{System structure}

Figure 1 shows the basic structure diagram of the DWC system, which consists of the primary side and the secondary side. At the primary side, multiple DWC transmitter modules include three coils are powered by a single inverter to reduce the number of the inverter. Each transmitter coil is compensated by a separate 
LCC compensation circuit. The transmitter coils are arranged in arrays to create a dynamic wireless charging lane. The transmitter is designed modular, which has many advantages. Firstly, it is possible to control ON/OFF the modules according to the position of the EV that the system efficiency increases and electromagnetic interference (EMI) reduce. Second, it is easy to expand the transmitter lane without changing the system design. At the secondary side, the receiver is installed beneath the EV chassis. The power is transferred from the primary side to the secondary side through the magnetic coupler. By resonating with the secondary LCC compensation circuit, the transferred power and efficiency are significantly improved. Then, the obtained AC voltage is rectified to charge the battery.

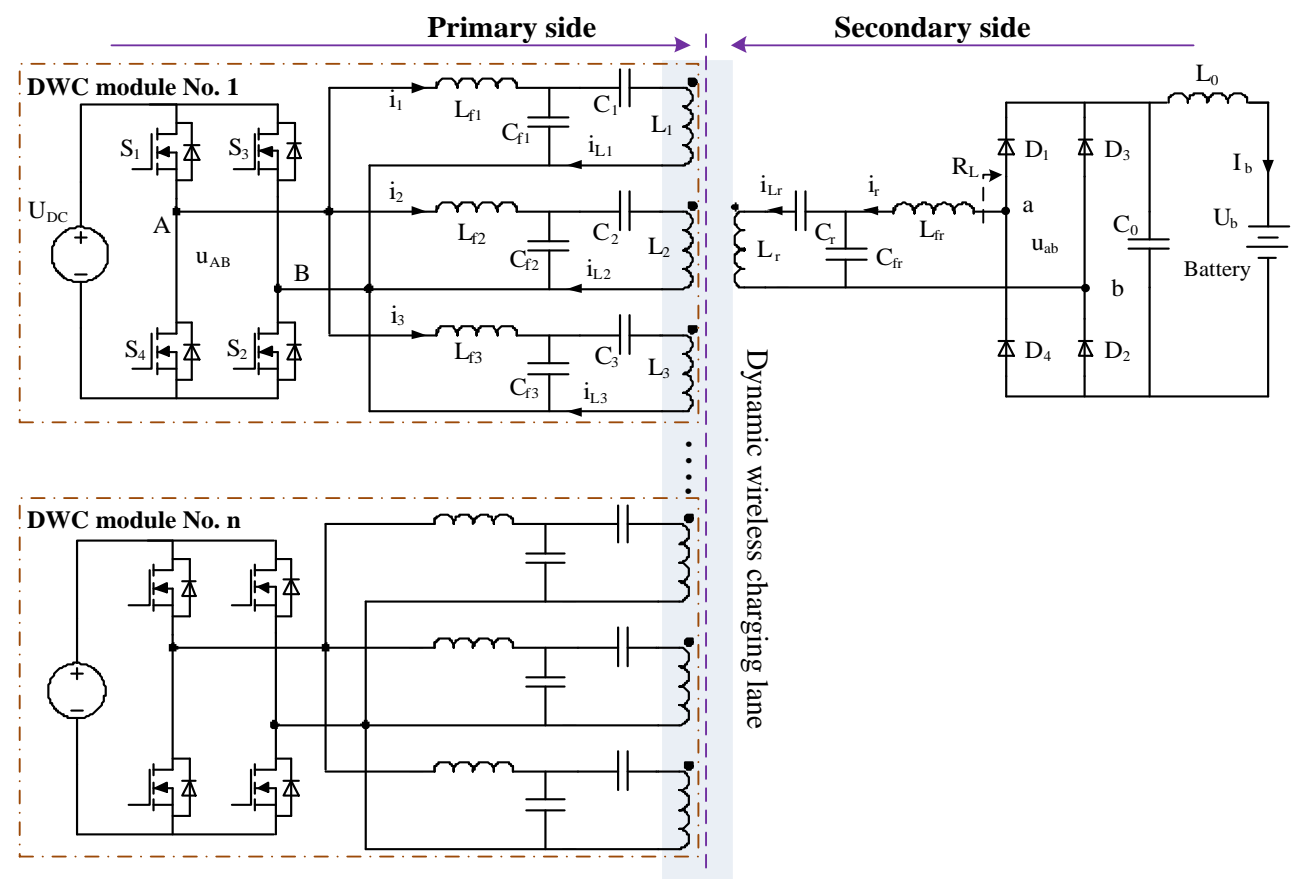

Figure 1. Structure diagram of the dynamic wireless charging

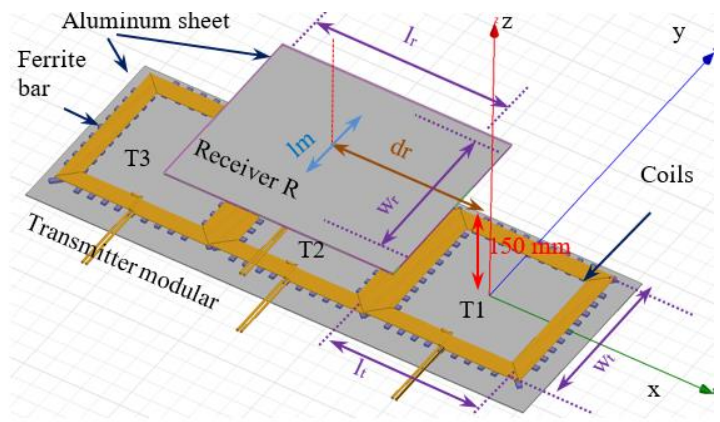

Figure 2. The 3-D maxwell magnetic coupler model of a DWC module

\subsection{Magnetic coupler design}

The 3-D maxwell magnetic coupler model of the DWC module is shown in Figure 2. The structure of a magnetic coupler consists of three layers. The top layer is the coil that is built by Stranded wire. The second layer is ferrite bars that used to increase the magnetic coupling. The bottom layer is the aluminum sheets that used to reduce magnetic field leakage. In this paper, the coil's design method is referenced in [14]. At the primary side, each DWC module has three unipolar transmitter coils which are arranged closely. The dimensions of each designed transmitter coil are $400 \mathrm{~mm}$ x $400 \mathrm{~mm}$ x $42 \mathrm{~mm}$. Each coil has 10 turns, the air gap distance is $150 \mathrm{~mm}$. The receiver displacement in the $\mathrm{x}$-direction is defined as $\mathrm{dr}$. When the center of the 
$\mathrm{R}$ receiver is straight with the center of the $\mathrm{T} 1$ transmitter, $\mathrm{dr}$ is zero. The distance between the center of $\mathrm{T} 1$ transmitter and the center of T3 transmitter equal to $800 \mathrm{~mm}$. Therefore, Therefore, $\mathrm{dr}$ is surveyed from $0 \mathrm{~mm}$ to $800 \mathrm{~mm}$. The lateral misalignment in the y-direction is defined as $\mathrm{lm}$. When the center of the receiver is straight with the center of transmitters, $1 \mathrm{~m}$ is zero.

In the WPT system, the output power is proportional to the coupling coefficient. Furthermore, in the DWC system, the coupling coefficient changes during charging. This design target is to reduce the coupling coefficient variation to reduce the output power pulsation in the dynamic charging process.

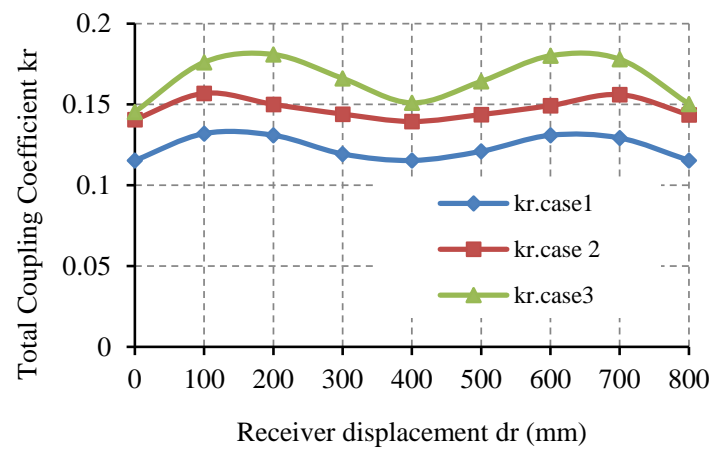

Figure 3. FEA simulation the total coupling coefficient $\mathrm{k}_{\mathrm{r}}$ when $\operatorname{lm}$ is zero

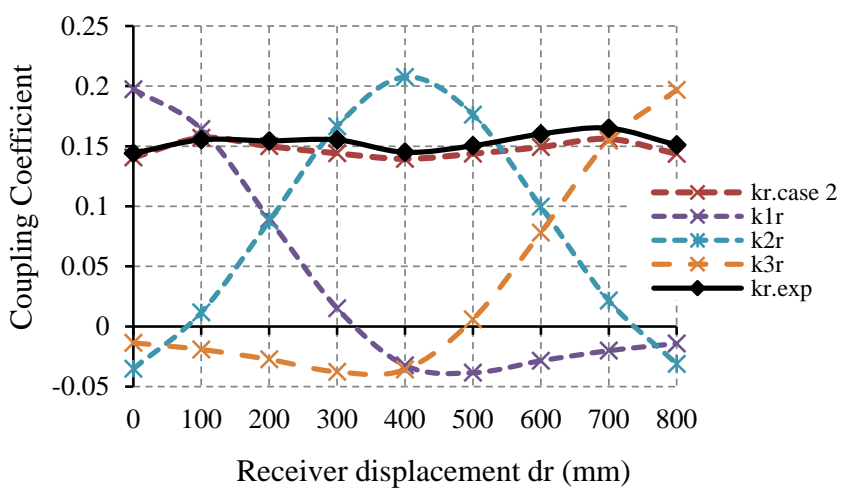

Figure 4. FEA simulation and experiment result of coupling coefficients

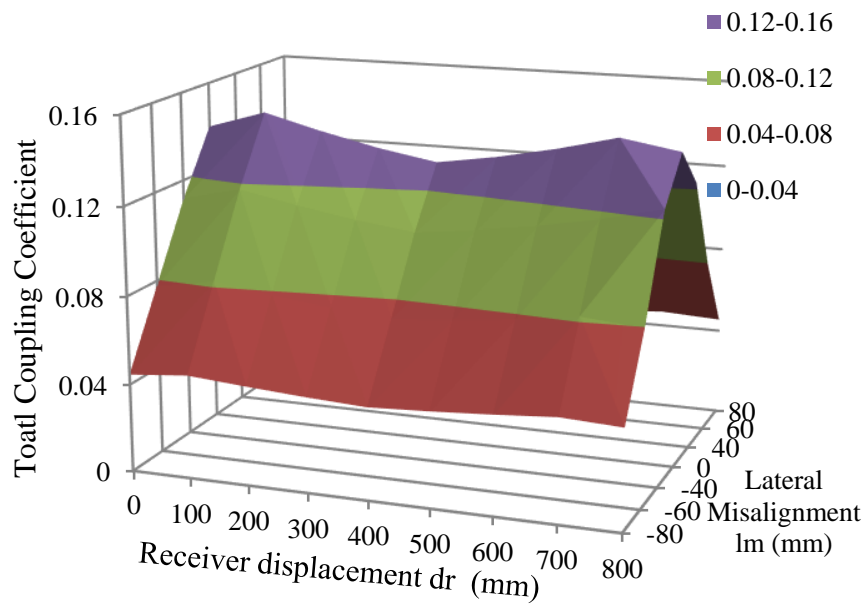

Figure 5. 3-D FEA simulation result of total coupling coefficients 


\begin{tabular}{|c|c|c|c|}
\hline Parameter & Value & Parameter & Value \\
\hline $\mathrm{L}_{\mathrm{i}}(\mathrm{i}=1,2,3)$ & $102 \mu \mathrm{H}$ & $\mathrm{M}_{1}$ & $11.937 \mu \mathrm{H}$ \\
\hline $\mathrm{L}_{\mathrm{r}}$ & $120 \mu \mathrm{H}$ & $\mathrm{M}_{2}$ & $20.903 \mu \mathrm{H}$ \\
\hline $\mathrm{k}_{\mathrm{r}}$ & 0.14 & $\mathrm{M}_{3}$ & $12.474 \mu \mathrm{H}$ \\
\hline
\end{tabular}

Initially, the receiver dimension is designed to same the transmitter dimension. Then, receiver dimension is analyzed and designed by EFA simulation. The coupling coefficients of each transmitter coil with the receiver coil are defined as $\mathrm{k}_{1 \mathrm{r}}, \mathrm{k}_{2 \mathrm{r}}, \mathrm{k}_{3 \mathrm{r}}$, respectively. The total coupling coefficient is determined as follows:

$$
k_{r}=k_{1 r}+k_{2 r}+k_{3 r}
$$

Figure 3 shows the total coupling coefficient FAE simulation results in three cases. In these cases, the receiver and transmitter coil width is chosen the same $\left(\mathrm{w}_{\mathrm{r}}=\mathrm{w}_{\mathrm{t}}=400 \mathrm{~mm}\right)$. The receiver coil length is varied during the analysis and design process. Where, $\mathrm{l}_{\mathrm{r}}, \mathrm{l}_{\mathrm{t}}, \mathrm{w}_{\mathrm{r}}, \mathrm{w}_{\mathrm{t}}$ is defined as length, width of the transmitter, receiver coil, respectively. In case $1: 1_{\mathrm{r}}=1_{\mathrm{t}}=400 \mathrm{~mm}$, the average total coupling coefficient is 0.128 , the variation is $9.9 \%$. In case $2: 1_{t}=500 \mathrm{~mm}$, the average total coupling coefficient increase to 0.14 , the variation decreases to $6 \%$. In case $3: 1_{\mathrm{t}}=600 \mathrm{~mm}$, the average total coupling continues to increases and equal to 0.165 . However, the variation also increases and is equal to $9.6 \%$. Thus, if the size of the receiver increases, the average total coupling coefficient also increases. However, the total coupling coefficient variation is not monotonic with the receiver size. In case 2, the variation is the lowest. Therefore, this value is chosen for the receiver design. The FAE simulation results of coupling coefficients in the case of the design is shown in Figure 4 (dot lines). The results show that the coupling coefficient $k_{i}$ increases when the receiver comes close to the Ti transmitter and decreases when the receiver moves away from the Ti transmitter $(\mathrm{i}=1,2,3)$. The measurement results of the total coupling coefficient are shown in Figure 4 (kr.exp - solid black line). The results show that the measured and simulated properties closely match. The parameters of the transmitters and receiver are summarized in Table 1. Sefl-inductance of transmitter and receiver coils are defined as $\mathrm{L}_{\mathrm{i}}, \mathrm{L}_{\mathrm{r}}$. The total mutual inductance of transmitter $\mathrm{L}_{\mathrm{i}}$ with other transmitters is defined as $\mathrm{M}_{\mathrm{i}}(\mathrm{i}=1,2,3)$.

When the lateral misalignment increases from 0 to $\pm 80 \mathrm{~mm}$, the 3-D FEA simulation result of total coupling coefficients are shown in Figure 5. The average total coupling coefficient decreases from 0.14 to 0.044 , which is the highest when the $1 \mathrm{~m}$ is zero. These results show that the total coupling coefficient varies when the receiver moves and decreases sharply when lateral misalignment increases.

\section{LCC COMPENSATION CIRCUIT DESIGN FOR MAXIMUM TRANSFER EFFICIENCY}

In this paper, the LCC compensation curcuit is designed for both side in the dynamic wireless charging system. At the primary side, the compensation circuit is designed to reduce the volt-ampere rating of the power converter and help achieve soft switching of the power electronics devices. At the secondary side, the compensation circuit is designed to maximize transfer efficiency. In this system, transmitter coils have selfcoupling that indicates in Table 1. The compensation circuit parameter design should consider all the selfcoupling. The resonant frequency is designed to be the switching frequency $\left(\mathrm{f}_{\mathrm{sw}}\right)$ which is $85 \mathrm{kHz}$ according to J2954 standard.

\subsection{Resonance circuit analysis}

The fundamental harmonics approximation is used to analyze the working principle of the resonance circuit. The inverter output voltage and rectifier input voltage were approximated as sinusoidal sources as shown in Figure 6a. The magnetic coupling between the coils is represented by current controlled voltage sources. Assuming that power losses of the elements in the circuit are negligible. Refer to the method of analyzing the resonant circuit in [14] to draw the following expressions.

The transmitter coils L1, L2, L3 are designed the same, so the self-inductance and mutual inductance are shown below.

$$
\left\{\begin{array}{l}
L_{1}=L_{2}=L_{3} \\
M_{\mathrm{ik}}=M_{k i}(i, k=1,2,3, i \neq k)
\end{array}\right.
$$

The receiver side compensation circuit parameters have the following relationship:

$$
C_{f r}=\frac{1}{\omega^{2} L_{f r}}
$$


$C_{r}=\frac{1}{\omega^{2}\left[L_{r}-L_{f r}\right]}$

At the transmitter side, the coupled voltage of transmitter coils are expressed as:

$U_{M i}=\sum_{k=1, k \neq i}^{3} j \omega M_{\mathrm{ik}} I_{L k} ; i=1,2,3$

The transmitter side compensation circuit parameters have the following relationship:

$\begin{aligned} C_{f i} & =\frac{1}{\omega^{2} L_{f i}} \\ C_{i} & =\frac{1}{\omega^{2}\left(L_{i}-L_{f i}+M_{i}\right)}\end{aligned}$
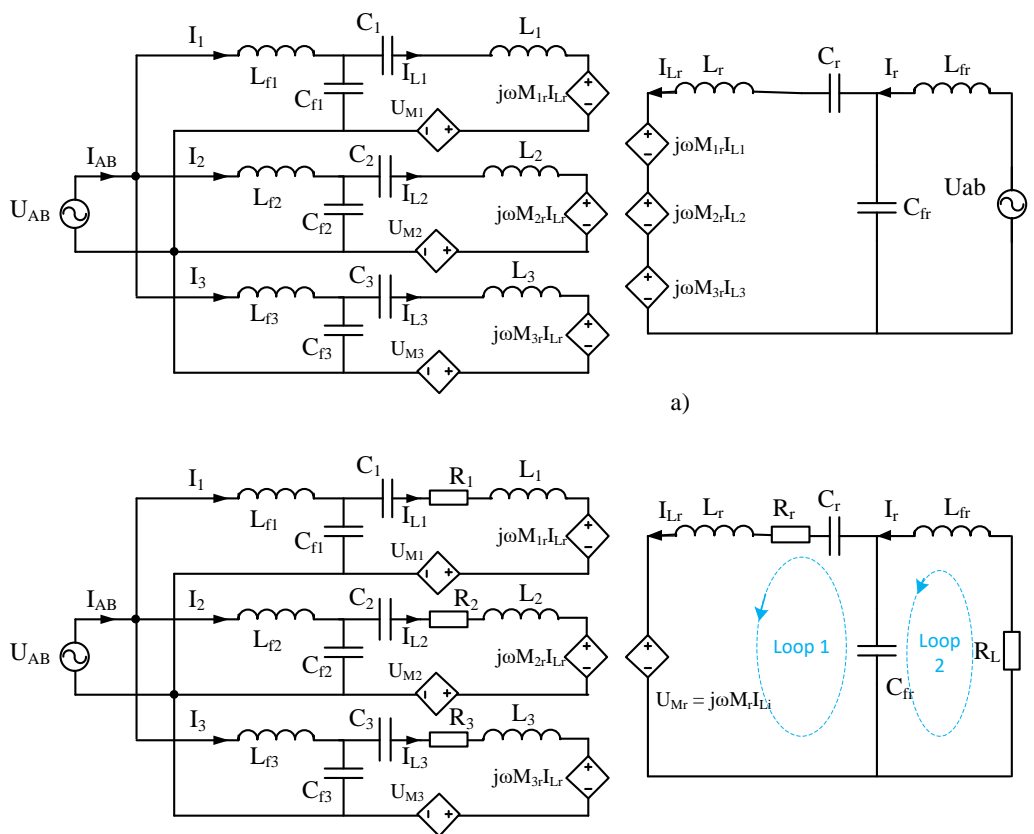

Figure 6. Equivalent resonant circuit

$L_{f 1}=L_{f 2}=L_{f 3}=L_{f i}$

$\left\{C_{f 1}=C_{f 2}=C_{f 3}=C_{f i}\right.$

At resonant condition, the resonant current of transmitter coils is expressed as

$I_{L 1}=I_{L 2}=I_{L 3}=I_{L i}=-j \omega C_{f i} U_{A B}$

Therefore, the coupled voltage of receiver coil with transmitter coils are

$$
\begin{aligned}
U_{M r} & =j \omega M_{1 \mathrm{r}} I_{L 1}+j \omega M_{2 \mathrm{r}} I_{L 2}+j \omega M_{3 \mathrm{r}} I_{L 3} \\
& =\sum_{i=1}^{3} j \omega M_{\mathrm{ir}} I_{L i}=j \omega M_{r} I_{L i} ; \text { with } M_{r} \\
& =\sum_{i=1}^{3} M_{\mathrm{ir}}
\end{aligned}
$$

Where $\omega$ is the resonant angular frequency, $\omega=2 \pi \mathrm{f}_{\mathrm{sw}}$; $\mathrm{i}(\mathrm{i}=1,2,3)$ is the index of the transmitter side parameters; $\mathbf{M}_{\mathrm{ir}}$ is mutual inductance of transmitters with the receiver.

\subsection{Optimal load conditions for maximum transfer efficiency}

Wireless power transfer system design for electric vehicle dynamic charging application (Nguyen Thi Diep) 
The equivalent circuit when considering the resistance of the transmitters and receiver is given in Figure $6 \mathrm{~b}$. Where, $\mathrm{R}_{\mathrm{i}}, \mathrm{R}_{\mathrm{r}}$ is transmitters resistance and receiver resistance, respectively. In the dynamic wireless charging, the battery is usually connected to the coil through a diode bridge rectifier. The battery could be equivalent to a resistance $R_{b}=U_{b} / I_{b}$, where $U_{b}$ and $I_{b}$ is the battery voltage and current, respectively. The equivalent ac side resistance could be calculated by $\mathrm{R}_{\mathrm{L}}=8 \mathrm{R}_{\mathrm{b}} / \pi^{2}$. Assuming that the power losses in components of the compensation circuit are negligible, at the secondary side, Kirchhoff 2 equations are for loop 1 and loop 2 as

$$
\left\{\begin{array}{l}
\left(R_{L}+j \omega L_{f r}\right) I_{r}+\frac{1}{j \omega C_{f r}}\left(I_{r}-I_{L r}\right)=0 \\
\left(\frac{1}{j \omega C_{r}}+R_{r}+j \omega L_{r}\right) I_{L r}+j \omega M_{r} I_{L i}-\frac{1}{j \omega C_{f r}}\left(I_{r}-I_{L r}\right)=0
\end{array}\right.
$$

The transfer efficiency can be expressed as:

$$
\eta=\frac{R_{L} I_{r}^{2}}{R_{L} I_{r}^{2}+R_{r} I_{L r}^{2}+R_{1} I_{L 1}^{2}+R_{2} I_{L 2}^{2}+R_{3} I_{L 3}^{2}}=\frac{R_{L}}{R_{L}+R_{r}\left(\frac{I_{L r}}{I_{r}}\right)^{2}+3 R_{i}\left(\frac{I_{L i}}{I_{r}}\right)^{2}}
$$

The ratio of the root-mean-square currents $\mathrm{I}_{\mathrm{Lr}} / \mathrm{I}_{\mathrm{r}}$ and $\mathrm{I}_{\mathrm{Li}} / \mathrm{I}_{\mathrm{r}}$ can be obtained by Error! Reference source not found. and combine with Error! Reference source not found., Error! Reference source not found.. The transfer efficiency can be determined as follows.

$$
\eta=\frac{R_{L}}{R_{L}^{2} \frac{R_{r}}{\omega^{2} L_{f r}^{2}}\left(1+\frac{3}{k_{r}^{2} Q_{i} Q_{r}}\right)+R_{L}\left(1+\frac{6}{k_{r}^{2} Q_{i} Q_{r}}\right)+\frac{3 \omega^{2} L_{f r}^{2} \quad 1}{R_{r} \quad k_{r}^{2} Q_{i} Q_{r}}}=f\left(R_{L}, k_{r}, Q_{i}, Q_{r}, f, L_{f r}\right)
$$

Where $\mathrm{Q}_{\mathrm{i}}=\omega \mathrm{L}_{\mathrm{i}} / \mathrm{R}_{\mathrm{i}}, \mathrm{Q}_{\mathrm{r}}=\omega \mathrm{L}_{\mathrm{r}} / \mathrm{R}_{\mathrm{r}}$ is transmitter coils quality factor, receiver coil quality factor, respectively. Equation Error! Reference source not found. show that transfer efficiency depends on parameters as $\omega, \mathrm{Q}_{\mathrm{i}}, \mathrm{Q}_{\mathrm{r}}, \mathrm{L}_{\mathrm{fr}}, \mathrm{k}_{\mathrm{r}}$, and $\mathrm{R}_{\mathrm{L}}$. In the WPT system, the frequency usually kept constant. Quality factors are fixed to the designated transmitter and receiver. The equivalent resistance value $\mathrm{R}_{\mathrm{L}}$ change according to the state of charge of the battery. Therefore, the maximum transfer efficiency is found by solving the equations:

$$
\frac{\partial \eta}{\partial R_{L}}=0 \text { and } \frac{\partial \eta^{2}}{\partial R_{L}^{2}}<0
$$

The maximum transfer efficiency:

$$
\eta_{\max }=\frac{k_{r}^{2} Q_{i} Q_{r}}{\left(\sqrt{3}+\sqrt{3+k_{r}^{2} Q_{i} Q_{r}}\right)^{2}}
$$

is achieved at:

$$
R_{L . o p t}=\frac{\omega^{2} L_{f r}^{2}}{R_{r}} \sqrt{\frac{3}{3+k_{r}^{2} Q_{i} Q_{r}}}
$$

Where $\mathrm{R}_{\text {L.opt }}$ is called the optimal impedance value. From Error! Reference source not found., Error! Reference source not found. show that transfer efficiency reaches a maximum value when the equivalent resistance value is optimal. Impedance matching network can be used to make equivalent resistance to its optimal value [16], [25]. The maximum theoretical transfer efficiency characteristic is shown in Figure 7. If quality factor $\mathrm{Q}_{\mathrm{i}}=419, \mathrm{Q}_{\mathrm{r}}=458$, and $\mathrm{k}_{\mathrm{r}}=0.14$, maximum theoretical transfer efficiency is about $94.6 \%$.

\subsection{Calculate parameter for LCC compensation circuit}

In this paper, a dynamic wireless charging system with a power of $1.5 \mathrm{~kW}$ is designed. And other required parameters are as the DC input voltage (UDC) is $310 \mathrm{~V}$, the output voltage on load (Uab) is $400 \mathrm{~V}$, the resonant frequency is $85 \mathrm{kHz}$. The output power can be calculated

$$
P_{\text {out }}=I_{r}^{2} R_{L}
$$


The output power can be obtained by Error! Reference source not found. and combine with Error! Reference source not found., Error! Reference source not found., Error! Reference source not found.:

$$
P_{\text {out }}=\frac{k_{r} \sqrt{L_{1} L_{r}}\left|U_{A B}\right|\left|U_{a b}\right|}{\omega L_{f} L_{f r}}-\frac{R_{r}}{\omega^{2} L_{f r}^{2}} U_{a b}^{2}
$$

The compensation circuit parameters are designed to satisfy the resonant conditions Error! Reference source not found., Error! Reference source not found., Error! Reference source not found., Error! Reference source not found., Error! Reference source not found., the optimal load conditions for maximum transfer efficiency Error! Reference source not found. and output power required Error! Reference source not found. Therefore, the system and compensation circuit parameter values are shown in Table 2.

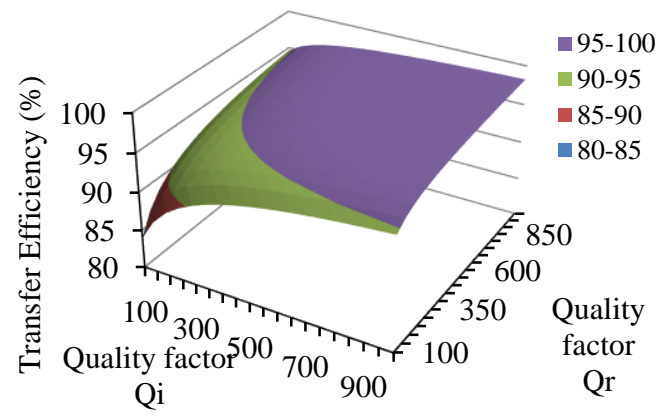

Figure 7. The maximum theoretical transfer efficiency characteristic with coupling coefficient is 0.14

Table 2. System and compensation circuit parameters

\begin{tabular}{cccc}
\hline Parameter & Value & Parameter & Value \\
\hline $\mathrm{L}_{\mathrm{i}}$ & $102 \mu \mathrm{H}$ & $\mathrm{C}_{1}$ & $93 \mathrm{nF}$ \\
$\mathrm{R}_{\mathrm{i}}$ & $0.13 \Omega$ & $\mathrm{C}_{2}$ & $123 \mathrm{nF}$ \\
$\mathrm{L}_{\mathrm{r}}$ & $120 \mu \mathrm{H}$ & $\mathrm{C}_{3}$ & $95 \mathrm{nF}$ \\
$\mathrm{R}_{\mathrm{r}}$ & $0.115 \Omega$ & $\mathrm{L}_{\mathrm{fr}}$ & $29 \mu \mathrm{H}$ \\
$\mathrm{C}_{\mathrm{fi}}$ & $66.5 \mathrm{nF}$ & $\mathrm{C}_{\mathrm{fr}}$ & $120 \mathrm{nF}$ \\
$\mathrm{L}_{\mathrm{fi}}$ & $52.6 \mu \mathrm{H}$ & $\mathrm{C}_{\mathrm{r}}$ & $38.5 \mathrm{nH}$ \\
& & $\mathrm{k}_{\mathrm{r}}$ & 0.14 \\
\hline
\end{tabular}

\section{SIMULATION AND EXPERIMENT RESULT}

\subsection{Simulation result}

High-order systems have multiple resonances frequency beyond the design frequency. This may significantly affect system efficiency when parameters change. Therefore, input impedance characteristics should be analyzed and considered. Figure 8, 9 is the simulation result of ANSYS Electromagnetics software. Figure 8 shows the simulation results of input impedance characteristics under different conditions. Figure $8 \mathrm{a}$ shows input impedance characteristics when $\mathrm{dr}$ is $0 \mathrm{~mm}, \mathrm{R}_{\mathrm{L}}$ varies from $10 \Omega$ to $140 \Omega$. The result shows that the system has multiple resonant frequencies in which a resonant frequency of $85 \mathrm{kHz}$ with any value of the load. Figure 8(b) shows input impedance characteristics when $\mathrm{R}_{\mathrm{L}}$ is $\mathrm{R}_{\mathrm{L} . \mathrm{opt}}$, dr varies from $0 \mathrm{~mm}$ to $500 \mathrm{~mm}$. The result shows that characteristic lines are nearly overlapping. There is a resonant frequency of $85 \mathrm{kHz}$ that is regardless of the receiver position. In high-frequency converters, MOSFET should be switched under ZVS (Zero Voltage Switching) conditions to reduce switching losses. Figure 8a shows that the ZVS region changes according to the load. Figure 8 (b) shows that when the load impedance value is optimal, the ZVS region is constant with all positions of the receiver.

Figure 9 shows the simulation results of transfer efficiency characteristics under different conditions. Figure 9a shows the transfer efficiency characteristics when the load $\mathrm{R}_{\mathrm{L}}$ varies from $10 \Omega$ to $140 \Omega$ and $\mathrm{dr}$ is 0 $\mathrm{mm}$. The results show that the transfer efficiency is the maximum value at the optimum load value. For other load values, transfer efficiency is reduced and drastically reduced at adjacent frequencies of $85 \mathrm{kHz}$. Figure $9 \mathrm{~b}$ shows the transfer efficiency characteristics when dr varies from $0 \mathrm{~mm}$ to $500 \mathrm{~mm}$ and $\mathrm{R}_{\mathrm{L}}$ is $\mathrm{R}_{\mathrm{L} . \text { opt. }}$ The results show that the transfer efficiency characteristics are almost overlapping. High transfer efficiency is achieved in the frequency range of $83 \mathrm{kHz}$ to $89 \mathrm{kHz}$. The highest transfer efficiency reached $94.6 \%$. 

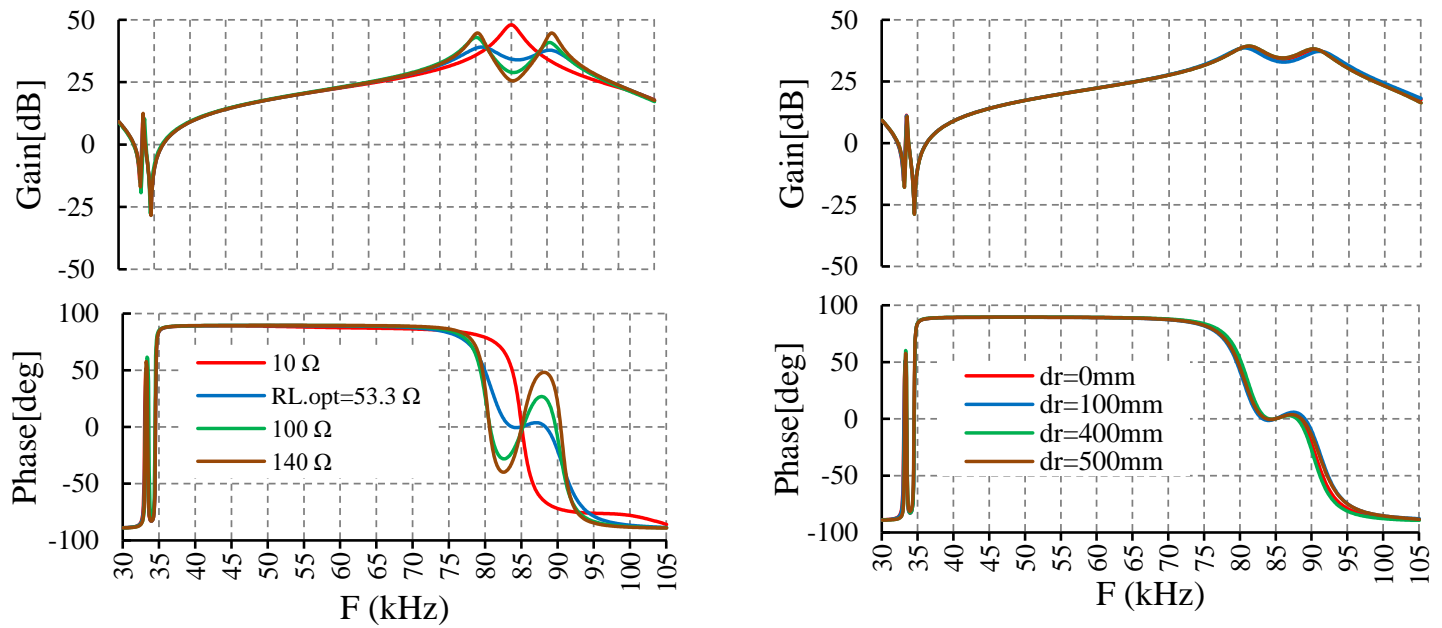

(a)

(b)

Figure 8. Frequency characteristics of input impedance (a) $d r=0 m m$ and $R_{L}$ is variation (b) $R_{L}=R_{L . o p t}$ and dr is variation

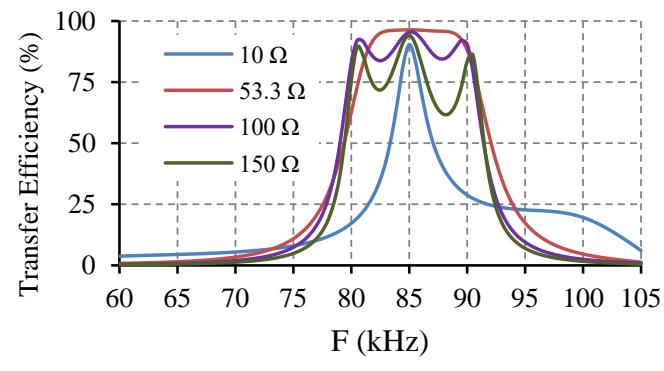

(a)

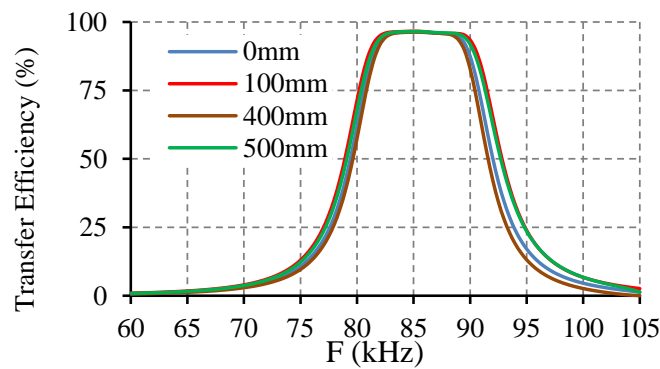

(b)

Figure 9. Frequency characteristics of the transfer efficiency (a) $d r=0 \mathrm{~mm}$ and $\mathrm{R}_{\mathrm{L}}$ is variation (b) $\mathrm{R}_{\mathrm{L}}=\mathrm{R}_{\mathrm{L} \text {.opt }}$ and $\mathrm{dr}$ is variation

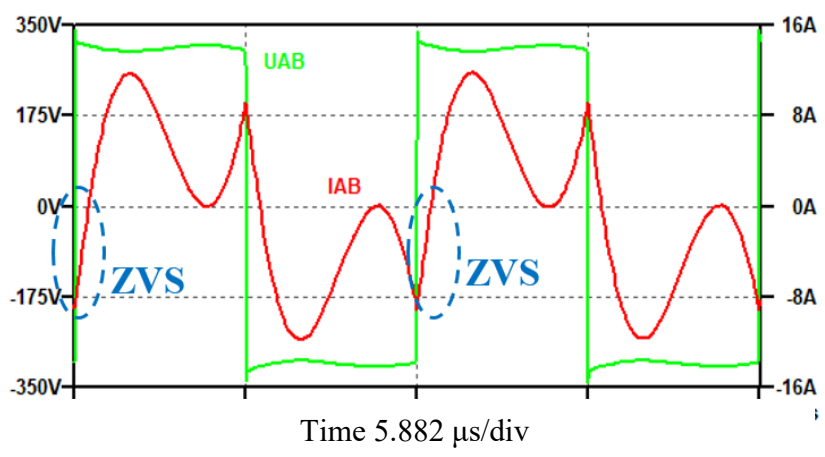

Figure 10. Simulation waveforms of voltage/current in LTspice 


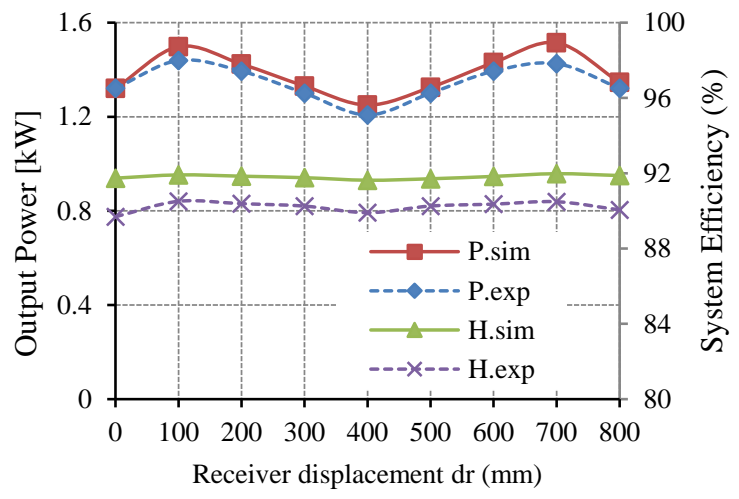

Figure 11. Simulation and experimental results of the output power and system efficiency

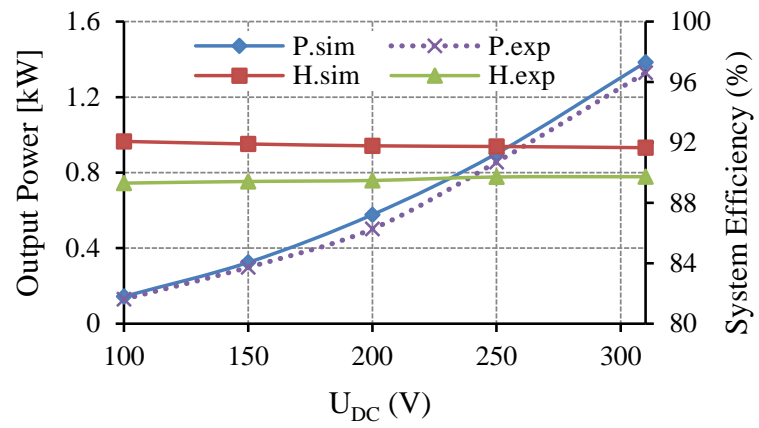

Figure 12. Simulation and experimental results of the output power and system efficiency at different $U_{D C}$ levels

A model was built in LTspice to simulate the efficiency from the DC input of the inverter to the output optimal load. Spice-model of MOSFET CMF20120D is used to build simulation models. Figure 10 shows the waveform simulation results of inverter output voltage/current when the receiver position $\mathrm{dr}$ is $0 \mathrm{~mm}$. This result shows that the MOSFET has achieved ZVS condition. When the receiver moves straight along the dynamic wireless charging lane, the simulation results of the output power and system efficiency are shown in Figure 11 (solid line). The average output power is $1.4 \mathrm{~kW}$ with a variation of $\pm 10 \%$. This result shows that the output power pulsation is improved. The average system efficiency reaches $91.8 \%$, of which the average transfer efficiency is $94.6 \%$, and the average inverter efficiency is $97 \%$. This result conforms with the theoretical analysis of the maximum transfer efficiency in section 3.2. When the receiver position is at $1 \mathrm{~m}=0$ $\mathrm{mm}$, the input voltage $\mathrm{U}_{\mathrm{DC}}$ varies from $100 \mathrm{~V}$ to $310 \mathrm{~V}$, the simulation results of the output power and system efficiency are shown in Figure 12 (solid line). The result shows that the output power varies from $0.14 \mathrm{~kW}$ to $1.4 \mathrm{~kW}$ which is consistent with the calculation formula Error! Reference source not found.. The average system efficiency reaches $91.7 \%$. This result shows that the system efficiency is high at different transfer power levels.

\subsection{Experiment result}

Figure 13 is an experimental setup in the laboratory environment. CMF20120D SICs have used to the full-bridge inverter. The polypropylene film capacitors are chosen for their low losses and high current bearing capability at high frequency. 


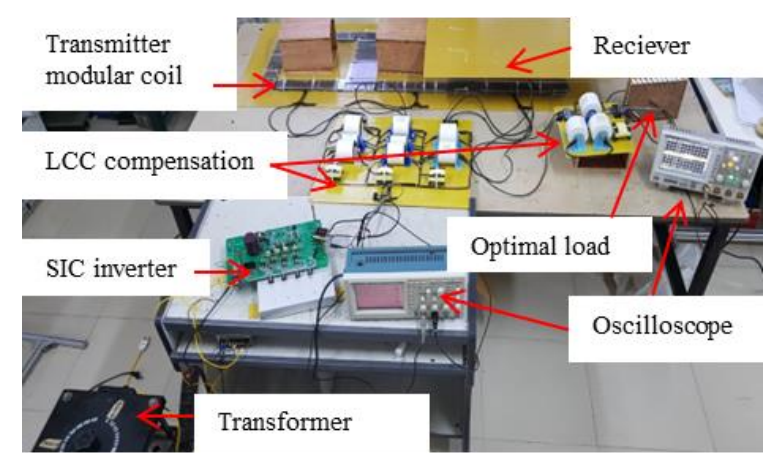

Figure 13. Experimental setup

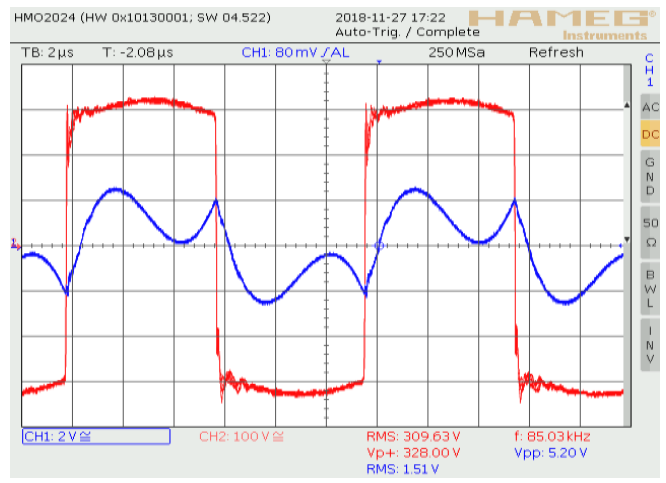

(a)

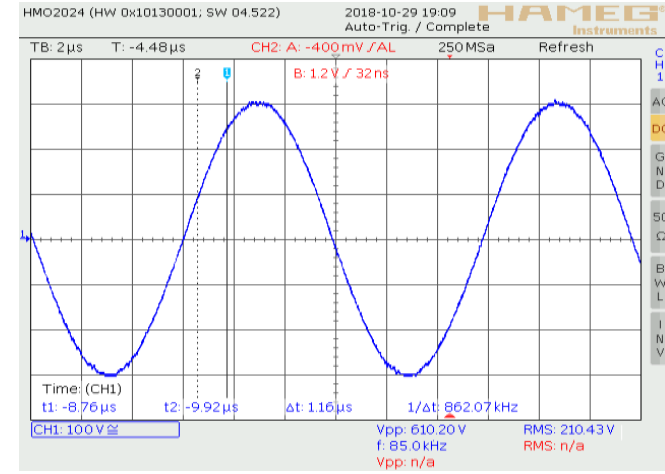

(b)

Figure 14. Experimental waveforms of voltage/current, (a) Output voltage/ current of the inverter, (b) The output voltage of the optimal load

The output voltage/current experimental waveform of the inverter is shown in Figure 14a, which is similar to the simulation results in Figure 10. The results show that the MOSFETs can achieve ZVS condition, the peak voltage stress is $328 \mathrm{~V}$, the peak current is $12.8 \mathrm{~A}$, $\mathrm{I}_{\text {off }}$ is $9.2 \mathrm{~A}$, the inverter's output frequency is $85 \mathrm{kHz}$ equal to the design frequency. Figure 14b shows the experimental waveform of the optimal load (measuring ratio is 3/4). The results show that the frequency of voltage on the load is $85 \mathrm{kHz}$. This means that the designed LCC compensation circuit has a resonant frequency equal to the design frequency suitable for input impedance analysis in Figure 8.

When the receiver straight moves along the dynamic wireless charging lane, the experimental results of the output power and system efficiency are shown in Figure 11 (dot line). The average output power is $1.38 \mathrm{~kW}$, the variation is $\pm 9.5 \%$. The average efficiency reaches $89.5 \%$. The experimental results show that it is consistent with the simulation results as well as theoretical analysis. When the inverter input voltage varies from $100 \mathrm{~V}$ to $310 \mathrm{~V}$, the experimental results of the output power, system efficiency shows in Figure 12 (dot line). The experimental results are quite close to the simulation results (solid lines). The output power varies from $0.129 \mathrm{~kW}$ to $1.33 \mathrm{~kW}$. The average system efficiency reaches $89.3 \%$.

\section{CONCLUSION}

This paper proposes and demonstrates a wireless power transfer system design for EV in DWC applications. The magnetic coupler design is optimized by FEA simulation to minimize the coupling coefficients variation during the charging process. The LCC compensation circuit parameters are calculated according to the optimum load value to maximize transfer efficiency. The results prove the feasibility of the proposed design method. The results indicate that the designed LCC compensation circuit has a resonance frequency of $85 \mathrm{kHz}$, independent of the coupling coefficients and load. The ZVS region for MOSFET is given. The maximum transfer efficiency simulation result reaches $94.6 \%$ that is consistent with the theoretical 
analysis. Experimental results indicate that the average output power is $1.38 \mathrm{~kW}$, the variation is $\pm 9.5 \%$, the average efficiency reaches $89.5 \%$.

\section{ACKNOWLEDGMENTS}

This research is funded by the Hanoi University of Science and Technology (HUST) under project number T2018-PC-054.

\section{REFERENCES}

[1] S. Lukic and Z. Pantic, "Cutting the Cord: Static and Dynamic Inductive Wireless Charging of Electric Vehicles," IEEE Electrification Mag., vol. 1, no. 1, pp. 57-64, Sep. 2013.

[2] L. Maglaras, F. Topalis, and A. Maglaras, "Cooperative approaches for dymanic wireless charging of Electric Vehicles in a smart city," ENERGYCON 2014 - IEEE International Energy Conference, 2014.

[3] S. Chopra and P. Bauer, "Driving Range Extension of EV With On-Road Contactless Power Transfer-A Case Study," IEEE Transactions on Industrial Electronics, vol. 60, no. 1, pp. 329-338, Jan. 2013

[4] C. Panchal, S. Stegen, and J. Lu, "Review of static and dynamic wireless electric vehicle charging system," Engineering Science and Technology, an International Journal, vol. 21, no. 5, pp. 922-937, Oct. 2018.

[5] S. Li and C. C. Mi, "Wireless Power Transfer for Electric Vehicle Applications," IEEE Journal of Emerging and Selected Topics in Power Electronics, vol. 3, no. 1, pp. 4-17, Mar. 2015.

[6] S. Lee, J. Huh, C. Park, N.-S. Choi, G.-H. Cho, and C.-T. Rim, "On-Line Electric Vehicle using inductive power transfer system," 2010 IEEE Energy Conversion Congress and Exposition, Atlanta, GA, 2010, pp. 1598-1601.

[7] J. Huh, S. W. Lee, W. Y. Lee, G. H. Cho, and C. T. Rim, "Narrow-Width Inductive Power Transfer System for Online Electrical Vehicles," IEEE Transactions on Power Electronics, vol. 26, no. 12, pp. 3666-3679, Dec. 2011.

[8] C. Liu, C. Jiang, and C. Qiu, "Overview of coil designs for wireless charging of electric vehicle," in 2017 IEEE PELS Workshop on Emerging Technologies: Wireless Power Transfer (WoW), Chongqing, China, 2017, pp. 1-6.

[9] J. M. Miller, P. T. Jones, J. Li, and O. C. Onar, "ORNL Experience and Challenges Facing Dynamic Wireless Power Charging of EV's," IEEE Circuits and Systems Magazine, vol. 15, no. 2, pp. 40-53, Secondquarter 2015.

[10] X. Zhang, Z. Yuan, Q. Yang, Y. Li, J. Zhu, and Y. Li, "Coil Design and Efficiency Analysis for Dynamic Wireless Charging System for Electric Vehicles," IEEE Trans. Magn., vol. 52, no. 7, pp. 1-4, Jul. 2016.

[11] K. Lee, Z. Pantic, and S. M. Lukic, "Reflexive Field Containment in Dynamic Inductive Power Transfer Systems," IEEE Trans. Power Electron., vol. 29, no. 9, pp. 4592-4602, Sep. 2014.

[12] S. Cui, Z. Wang, S. Han, and C. Zhu, "Analysis and Design of Multiphase Receiver With Reduction of Output Fluctuation for EV Dynamic Wireless Charging System," IEEE Trans. Power Electron., vol. 34, no. 5, pp. 41124124, May 2019.

[13] H. Li, Y. Liu, K. Zhou, Z. He, W. Li, and R. Mai, "Uniform Power IPT System With Three-Phase Transmitter and Bipolar Receiver for Dynamic Charging," IEEE Transactions on Power Electronics, vol. 34, no. 3, pp. 2013-2017, Mar. 2019.

[14] F. Lu, H. Zhang, H. Hofmann, and C. C. Mi, “A Dynamic Charging System With Reduced Output Power Pulsation for Electric Vehicles," IEEE Trans. Ind. Electron., vol. 63, no. 10, pp. 6580-6590, Oct. 2016.

[15] N. T. Diep, N. K. Trung, and T. T. Minh, "Power Control in the Dynamic Wireless Charging of Electric Vehicles," in 2019 10th International Conference on Power Electronics and ECCE Asia (ICPE 2019 - ECCE Asia), 2019, pp. $1-6$.

[16] N. T. Diep, N. K. Trung, and T. T. Minh, "Maximum Efficiency in the Dynamic Wireless Charging Systems of Electric Vehicles," in 2019 10th International Conference on Power Electronics and ECCE Asia (ICPE 2019 ECCE Asia), 2019, pp. 1-6.

[17] C. Duan, C. Jiang, A. Taylor, and K. (Hua) Bai, "Design of a zero-voltage-switching large-air-gap wireless charger with low electric stress for electric vehicles," IET Power Electronics, vol. 6, no. 9, pp. 1742-1750, Nov. 2013.

[18] W. Zhang, S.-C. Wong, C. K. Tse, and Q. Chen, "Analysis and Comparison of Secondary Series- and ParallelCompensated Inductive Power Transfer Systems Operating for Optimal Efficiency and Load-Independent VoltageTransfer Ratio," IEEE Trans. Power Electron., vol. 29, no. 6, pp. 2979-2990, Jun. 2014.

[19] S. Cho, I. Lee, S. Moon, G. Moon, B. Kim, and K. Y. Kim, "Series-series compensated wireless power transfer at two different resonant frequencies," 2013 IEEE ECCE Asia Downunder, 2013, pp. 1052-1058.

[20] K. Uchida and K. Akatsu, "An Examination of Optimizing Input Impedance for Wireless Power Transfer Operating with High Power Condition," 2017 IEEE 3rd International Future Energy Electronics Conference and ECCE Asia (IFEEC 2017 - ECCE Asia), 2017, pp. 633-637.

[21] D. M. Vilathgamuwa and J. P. K. Sampath, "Wireless Power Transfer (WPT) for Electric Vehicles (EVs)—Present and Future Trends," Plug In Electric Vehicles in Smart Grids, S. Rajakaruna, F. Shahnia, and A. Ghosh, Eds. Singapore: Springer Singapore, 2015, pp. 33-60.

[22] V.-B. Vu, D.-H. Tran, and W. Choi, "Implementation of the Constant Current and Constant Voltage Charge of Inductive Power Transfer Systems With the Double-Sided LCC Compensation Topology for Electric Vehicle Battery Charge Applications," IEEE Trans. Power Electron., vol. 33, no. 9, pp. 7398-7410, Sep. 2018.

[23] Q. Zhu, L. Wang, Y. Guo, C. Liao, and F. Li, "Applying LCC Compensation Network to Dynamic Wireless EV Charging System,” IEEE Trans. Ind. Electron., vol. 63, no. 10, pp. 6557-6567, Oct. 2016.

[24] M. Kim, D. Joo, and B. K. Lee, "Design and Control of Inductive Power Transfer System for Electric Vehicles Considering Wide Variation of Output Voltage and Coupling Coefficient," IEEE Transactions on Power Electronics, vol. 34, no. 2, pp. 1197-1208, Feb. 2019. 
[25] Y. Huang, N. Shinohara, and T. Mitani, "Impedance Matching in Wireless Power Transfer," IEEE Trans. Microwave Theory Techn., vol. 65, no. 2, pp. 582-590, Feb. 2017.

\section{BIOGRAPHIES OF AUTHORS}

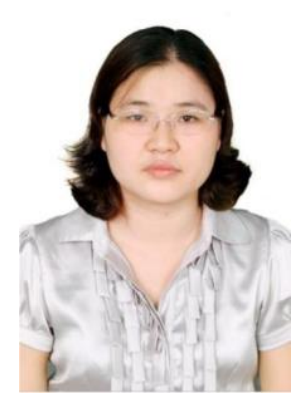

Nguyen Thi Diep received the B.E degree and M.S degree from the Hanoi University of Science and Technology, Hanoi, Vietnam, in 2004 and 2008. She is currently working toward the Ph.D. degree in the Hanoi University of Science and Technology, Hanoi, Vietnam. She works as a lecturer at Electric Power University.

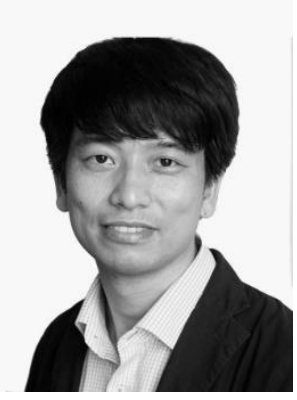

Nguyen Kien Trung was born in Hanoi, Vietnam. He received the B.E. and M.Sc. degrees in control and automation from Hanoi University of Science and Technology, Vietnam in 2008 and 2011, respectively. In 2016, he received the Ph.D. degree in Functional control systems at Shibaura Institute of Technology, Japan, where he worked as a postdoctoral researcher in 2016-2017. From 2018, he works as a lecturer at Hanoi University of Science and Technology. Dr. Trung is a member of the IEEE and IEE of Japan.

His research interests include high-frequency converters and wireless power transfer systems.

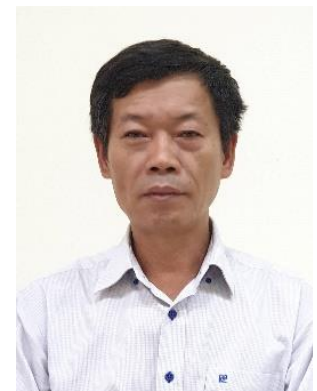

Tran Trong Minh receiver the Ph.D. degree from Hanoi University of Science and Technology, Vietnam in 2008. Now, he works as a lecturer at Hanoi University of Science and Technology. His research interests include power electronics, wireless power transfer systems. 